\title{
THERE ARE NO PURELY AESTHETIC OBLIGATIONS
}

\author{
BY
}

JOHN DYCK

\begin{abstract}
Do aesthetic reasons have normative authority over us? Could there be anything like an aesthetic 'ought' or an aesthetic obligation? I argue that there are no aesthetic obligations. We have reasons to act certain ways regarding various aesthetic objects - most notably, reasons to attend to and appreciate those objects. But, I argue, these reasons never amount to duties. This is because aesthetic reasons are merely evaluative, not deontic. They can only entice us or invite us - they can never compel us. Beauty gives us goods without shoulds.
\end{abstract}

Some evaluative realms have strong normative force. There are moral obligations; morality issues demands that we ought to follow, and it is wrong to do otherwise. Perhaps there are epistemic obligations, too. ${ }^{1}$ What about beauty? Are there aesthetic obligations? This is the core question I'll address. In particular, the core question is whether aesthetic reasons are normatively strong - whether these reasons compel us and make demands of us.

The core question is related to practical decisions we make about how seriously we should take beauty in our everyday lives. Is it okay to just sit at home instead of going to that jazz show tonight? Is it okay to listen to Nickelback? But it also presents a deep question about the nature of normativity: Is there a constitutive relationship between evaluation and obligation? Or can a realm like aesthetics be evaluative without involving obligation?

The idea that there are aesthetic obligations has some intuitive support. Our aesthetic language invokes normatively strong reasons. John Broome says: 'I once advised a guest that he ought to eat a mangosteen because mangosteens are delicious. I was speaking correctly. "Ought" is certainly not particularly a moral word.' (Broome 2013, p. 8). I've been told that I ought 
to use Punt e Mes vermouth when I make an Americano. I've been told that I should not listen to Nickelback. And besides the linguistic evidence, there are intuitive aesthetic oughts. If a lunar eclipse is happening, your children should watch the eclipse instead of playing around on their phones. ${ }^{2}$ Furthermore, in the recent discussion of aesthetic obligations, nearly all discussants accept that there are aesthetic obligations, either giving arguments for them or accounts of them (Archer and Ware 2017, 2018; Cross 2017b; Eaton 2008; Kubala 2018; Lopes 2018; McGonigal 2018; Sharpe 2000).

I'll argue to the contrary that aesthetic reasons are never normatively strong. Here's a slogan: Beauty gives us goods without shoulds. (The slogan is slightly misleading for reasons I'll explore later, but it'll do for now.) Beauty may seem to issue demands, but they vanish under a closer look. My goal here is twofold. First, I argue against several strategies for establishing aesthetic obligations. Second, I present and motivate a metanormative structure of aesthetic reasons according to which aesthetic reasons never compel.

I begin by considering what aesthetic obligations would look like if they existed; I'll give an account of obligations in terms of normative strength. Aesthetic reasons become obligations when those reasons are deontic when they make demands that it would be wrong to ignore. In $\S 2$, I consider some accounts of aesthetic obligations, and raise worries about these accounts. I show that the strongest case for aesthetic obligations rests on a common view about the normative structure of reasons in general: all reasons, including aesthetic reasons, are deontic. In $\S 3$, I sketch an alternative view from Jonathan Dancy that some reasons do not demand. According to this view, some reasons are not deontic, but merely enticing. In $\$ 4$, I apply this view to the aesthetic realm: Aesthetic reasons are enticing. I argue that this view explains the freedom we have in the aesthetic realm. In $\S 5$, I consider some objections.

\section{Characterizing aesthetic obligations}

What are obligations in general? I'll work with an account of obligations that falls in line with previous discussions of aesthetic obligations. It is common to think of obligations in kinetic metaphors, as reasons that have 'force' or 'binding weight'. In a discussion of the duties of love, R. Jay Wallace comments that there is a 'peremptory or decisive aspect that distinguishes obligations from other kinds of normative consideration' (2013, p. 192). In his account of aesthetic obligations, Robbie Kubala draws on Wallace, claiming that obligatory reasons involve a 'demand' or 'requirement' (Kubala 2018, p. 271). Marcia Muelder Eaton agrees that obligations are 'demands' (Eaton 2008, p. 1). I will assume here that obligations in general are reasons that issue requirements. ${ }^{3}$ The crucial issue, then, is whether 
aesthetic reasons ever amount to demands; whether they are what I will call deontic. Deontic reasons are reasons that make demands; a demand is a consideration that it would be wrong to ignore in the face of further reasons to the contrary.

Again, the terminology can get messy. Perhaps not all oughts rise to the level of obligations. We will return to this issue later. For now, the point is just that many oughts $d o$ issue demands. This suggests that aesthetic reasons have some heft to them in the kinetic sense that indicates obligation.

If obligations in general are demanding reasons, then aesthetic obligations derive from aesthetic reasons that make demands. So what are aesthetic reasons? A definition would be too much here, but we can work with two conditions. First, aesthetic reasons centrally involve aesthetic properties. Aesthetic reasons need not reduce to aesthetic properties. ${ }^{4}$ But aesthetic properties must figure in some robust way - some way in which the aesthetic is central. Some reasons are related to aesthetics, but not centrally so. They derive their force from morality or politics. In older argument for aesthetic obligations, Howard Press argued that there is at least one aesthetic obligation: 'One ought to appreciate what is beautiful' (Press 1969, p. 525). Press's argument relies upon the moral salience of aesthetic appreciation: 'in the appreciation of beauty, ... we exercise a power, a moral power, and ... the exercise of this power involves moral achievement' (525). If aesthetic appreciation is an essential part of moral development, it is easy to show that there are aesthetic obligations. But this is separate from my question - which I take to be the crucial question of aesthetic obligations - of whether aesthetic reasons have deontic force on their own. So I will restrict myself to aesthetic reasons which centrally involve aesthetic properties.

Second, and perhaps more controversially: aesthetic reasons centrally involve certain mental attitudes such as attention and/or appreciation: aesthetic obligations are cases where aesthetic reasons provide a binding reason to appreciate or attend to something. Why take appreciation and attention to be central to aesthetic reasons? The question is all the more salient because there is exciting recent work that underscores the importance of aesthetic action. As Cross (2017a), King (2018), and Lopes (2018) point out, aesthetic reasons do not just involve reasons to appreciate; they also involve reasons for actions: hanging drywall, selecting a Honeycrisp apple rather than a Gala, paying the bus fare to get to the theater. While aesthetic action is important, I maintain here that appreciation and attention are central to aesthetic reasons. For one thing, attention and appreciation have been paradigmatic in several important accounts of aesthetic obligations (Kubala 2018; McGonigal 2018). For another thing, while aesthetic action-involving reasons are indeed crucial and underexplored, the force of those reasons seems to derive from the centrality of appreciation to the aesthetic realm. No doubt our aesthetic lives are broader than mere appreciation. Yet, as Keren Gorodeisky (Forthcoming) argues, these actions seem 
to rest upon the centrality of appreciation. You select the Honeycrisp apple over the Gala because it will lead to a tastier galette - tastiness is a value that centrally involves appreciation. Your reason for driving to the theater, if it is aesthetic, derives from the value of the movie you are going to see, which is centrally related to its worthiness for attention. ${ }^{5}$

Aesthetic obligations, then, are deontic aesthetic reasons - aesthetic reasons with demanding force - where 'aesthetic reasons' centrally involve aesthetic properties and an attitude of appreciation.

\section{Three strategies}

With an intuitive understanding of aesthetic obligations in place, let's consider three prominent strategies for establishing aesthetic obligations. ${ }^{6}$

\subsection{THE THOUGHT EXPERIMENT STRATEGY}

The first strategy is an appeal to intuition. Some philosophers present intuitive cases - thought experiments which are meant to show decisively that there are aesthetic obligations. Call this the Thought Experiment Strategy.

Marcia Muelder Eaton presents burning museum cases. Suppose that you can save only one of two paintings from a burning building, "paintings that you believe are equal in moral value'. Suppose one of these paintings is more beautiful than the other. Eaton writes: 'I believe that you have an uncontroversial, nonconditional aesthetic obligation to save one rather than the other, namely, the more beautiful painting' (Eaton 2008, p. 5). Andrew McGonigal presents drowning art cases - cases where you can easily prevent the destruction of a beautiful artwork if it costs very little (say, getting your clothes wet). In such cases, McGonigal claims, you clearly ought to save the artwork.

Both thought experiments appeal to relatively objective or quasi-realist aesthetic properties. The way they are presented, the obligations are not rooted in any personal relation or attachment one bears to the object, nor are they rooted in unique sensibilities. The obligations are rooted in the objective aesthetic value of the paintings.

But this raises doubts about how truly aesthetic the obligations are. Perhaps we are smuggling in historical properties to pass as aesthetic value in the thought experiments. Consider the drowning art case. The intuition that we ought to save the more beautiful painting may be rooted in the thought that we ought to save the painting with more art-historical or cultural importance. For the intuition does not seem to change in an aesthetic Twin Earth scenario when we suppose that the painting has no aesthetic value. Suppose, for example, that the painting in danger is regarded by nearly everyone as very beautiful. In fact, only you know that the painting has no aesthetic 
value. Yet it still seems clear that you ought to save the painting, just because it is held in very high regard by nearly everybody. This suggests that you ought to save paintings that more people enjoy, or paintings that have art-historical importance. If true, this suggests that art-historical importance - not objective aesthetic value - creates a duty to save these painting.

Even if you find the Thought Experiment Strategy compelling, two problems are looming. First: At best these cases provide a question rather than an answer. Suppose these cases establish that there are aesthetic obligations. If there are aesthetic obligations, what is their normative structure? The obligations are presumably underwritten by the beauty of the objects in question. How could beauty give rise to such obligations? This is the core question about aesthetic obligation. The Thought Experiment Strategy does not offer an answer.

Second: these intuitive cases do not involve appreciation or attention, the paradigmatic act of aesthetic obligation. For the Thought Experiment Strategy to be convincing, we need a story about how our obligations to save these artworks are rooted in obligations to attend to or appreciate these works. But no one has offered such an explanation. And none seems forthcoming, either - just because you save them, does it mean people ought to look at them? Absent such a story, these actions do not seem like they will establish aesthetic obligations in the sense that matters for the core question.

\subsection{THE RELATIONAL STRATEGY}

The second strategy is both reductive and relational: Aesthetic obligations are instances of more general obligations brought about by relations, either to oneself or to something else. This strategy is developed along different lines by Anthony Cross, Robbie Kubala, and Andrew McGonigal. Call this the Relational Strategy.

On Cross's account, aesthetic obligations exist as instances of duties of love. ${ }^{7}$ Cross describes duties of love as follows: they are 'obligations to some individual that one incurs in virtue of standing in a particular relationship to that individual - namely, a loving relationship' (McGonigal 2017, p. 96). Because we love artworks, we incur obligations that result from relationships of love. We owe it to ourselves to appreciate some artworks. Cross's picture consists of two stages. At a first stage, we develop relationships with artworks, just like we develop relationships with people. Certain movies, paintings, or albums become important to our practical identities. At a second stage, we make commitments to these objects in virtue of the value they have for our own practical identities. Think of the punk, the metalhead, the opera lover, the hophead, the foodie. These types of fans have practical commitments to distinct kinds of beauty. Those commitments provide deontic reasons for attention and appreciation of art. Cross notes, crucially, that commitments to art must be merited by qualities in the artworks, just as 
commitments to friends must be merited by qualities of friends. There are no obligations to love bad art.

On Kubala's account, aesthetic obligation is based not in commitment, but in promising: it is 'a species of promissory obligation, namely selfpromising' (Kubala 2018, p. 271). Kubala invokes a passage from Proust, in which Marcel promises to return to admire the hawthorns. According to Kubala's account, Marcel promises to become the kind of person who attends to hawthorns, and therefore creates an obligation for himself to attend to hawthorns. ${ }^{8}$ Kubala argues that we have obligations to ourselves - obligations borne of self-promises - to attend to things. These self-promises are rooted in practical identities, especially as fans and aficionados. ${ }^{9}$ You should not neglect punk shows if you are a punk; you should not neglect Springsteen's Nebraska if you are a Springsteen fan. Kubala's account is a self-promise account of aesthetic obligation; the obligation is rooted from promises we make to ourselves in virtue of our own practical identities. The promises provide deontic reasons.

McGonigal offers an account based on integrity: We have obligations to ourselves to honor our own aesthetic preferences. We should pursue aesthetic projects that authentically express the kinds of things we like and the kinds of people we are. If you consider yourself a foodie, you ought to check out the new food truck on campus instead of going to the crappy cafeteria for the fourth time this week.

These three accounts share two main features. First, they are all grounded in individual or personal relationships, primarily to one's self. They rely on similar relations - relationships, self-promising, and integrity - all of which place obligations squarely in one's own self-conception, act of commitment, or practical identity. ${ }^{10}$ The second main feature is that they all appeal to practical identities or self-conceptions that are importantly related to deep personal attachments. On all these views, aesthetic obligations relate to something like fanhood. Commitment, self-promising, and integrity all depend not just on a high regard for some artwork, object, or practice, but on one's incorporating that aesthetic object into their sense of self - their practical identity.

These features give rise to several problems. First, because these accounts are all rooted in deep personal attachments, the scope of aesthetic obligations is now smaller than we might have thought. On these accounts, aesthetic obligations arise only as relations between fans and the objects, genres, or works that they are fans of. This does not explain the cases of aesthetic obligations mentioned at the outset: The thought that my child should put his phone down and see the sunset, for example. These putative obligations are not rooted in personal attachments. If you find those cases in need of an explanation, the Relational Strategy will not help you.

A second objection requires a little more set-up. It begins from a separate, more familiar objection: Aesthetic reasons are not up to the task of 
providing things worthy of commitment, integrity, or self-promises, because they can be undone by one's self. Because we can opt out of them, the commitments are meaningless. Obligations of our practical identities, or obligations of integrity, have no hold on us when we change our practical identities. As a metalhead, Jill ought to listen to Iron Maiden's The Number of the Beast. But if Jill relinquishes her practical identity as a metalhead, it seems that she no longer has an obligation to listen to any metal - she can simply release herself from the obligation. Or she can commit to a more particular identity that gets her off the hook from listening to that album (she might avow a practical identity as a metalhead who does not listen to Iron Maiden albums, or to that Iron Maiden album) and thereby avoid this obligation. We are left with the question of how aesthetic reasons could evince authority over ourselves. If we can change our practical identities anyways, do aesthetic reasons present deontic force at all?

Cross confronts this objection head on (Unpublished MS.). In reply, he rightly points that one can have obligations even if it is possible to be released from them. For instance, I have obligations while I'm married. But I'm released from those obligations if my spouse and I end our marriage. The fact that I can release myself from obligations does not show that they do not exist in the first place; it just shows that they can be changed. Not all commitments are lifelong. Temporary commitments are still commitments. Granting this to the Relational Strategy, though, notice that familiar commitments from self-promises, relationships, and integrity are usually codified in some form - marriages and jobs involve formal promises, codified in vows and contracts. Even commitments to go to lunch are spoken, texted, agreed upon. But our aesthetic lives aren't often characterized by codification. Relationships to artworks rarely involve explicit promises. Either these relationships do not occur very often (because they are not codified very often), or they involve an implicit structure that needs to be spelled out more.

In fact, when we think more about specific cases, it's not clear that many fans have personal connections with art that are deep enough to count as commitment, self-promising, or integrity. Do fans ordinarily make commitments to the objects of their fanhood? Certainly some do; Kubala gives an excellent example of a devoted opera fan. But many people - and many fans - do not make anything like promises to themselves; nor do they develop relationships of commitment with aesthetic objects; nor does their integrity lie on the aesthetic objects they appreciate. I'm a fan of several genres. I stay up with new releases, attend shows, and read reviews. But I would not say I've made a commitment to those genres, or that my integrity rests upon my appreciation for them, or that I've made a promise to myself regarding my future pursuit of them. As Cheshire Calhoun (2009) points out, commitment (or integrity, or promising) implies a future-directed diachronic attitude regarding one's future self: in the aesthetic realm, this means a 
commitment to stand firm in one's appreciation come what may. In the aesthetic realm, however, I keep things open; I come back to Kanye West with fresh ears every once in a while, willing to hear his music in a new way. I'm open to seeing it in a new light. The central point here - one which I will return to later - is that our aesthetic loves certainly exist, but they are open to revision. They can be adapted, revamped, canned, and updated. We have freedom in our aesthetic pursuits; the Relational Strategy does not reflect that freedom.

The third problem with these accounts is that they paint an overly narrow picture of a proper aesthetic life. If there can be commitments that compel us to attend to and appreciate art, then such commitments can also compel us not to attend to and appreciate art. I can make a promise to myself not to listen to punk, or jazz, or rap. But that does not quite feel right.

Imagine that you have Marcel over one night. After a third round of drinks, you really want to blow his aesthetic mind. You put on Gram Parson's 1974 album Greivous Angel. Given Marcel's practical identity as an urbane and sensitive aesthete, he has made a self-promise against listening to that twangy country sound. So, it seems, if commitments are loose enough to be gained in the way suggested above, then Marcel has an obligation not to attend to the country music. But this is absurd. Surely Marcel should indulge you and give it a listen.

One might object at this point that Marcel also has an obligation to be kind and obliging to his friends, and to that extent Marcel ought to listen. The obligation to be kind outweighs the obligation not to listen. But even if the aesthetic obligation is overridden, notice that Marcel still has a deontic reason not to listen. It seems strange that we could evince obligations to not attend to some artworks. But this is what the view implies.

Fourth, a point of internal consistency: Both Cross and McGonigal appeal to the intuitive cases of burning and drowning art to motivate the view that aesthetic obligations exist in the first place. But the Relational Strategy cannot explain the intuitive cases in the Thought Experiment Strategy. In the intuitive cases, the obligation is rooted in the objective (or at least quasi-realist) aesthetic value of the artworks. According to the Relational Strategy, aesthetic obligations rest ultimately in personal orientations or attitudes. If the intuitive cases are supposed to motivate the view that there are aesthetic obligations for the Relational Account, the Relational Account ought to accommodate them as genuine instances of aesthetic obligations. But it cannot. To the extent that you find those intuitive cases in need of an explanation, the Relational Strategy will not help you.

In fact, The Relational Strategy can start to chafe against the intuitive cases. Let us go back to the burning museum case. Suppose I have developed a strong personal relationship with the less beautiful painting - the painting in the Bad Art wing rather than in the Post-Impressionism wing. According to these relational accounts, I ought to save the painting I have a love for, 
not the most beautiful painting. But Eaton thought it was clear that I ought to save the more beautiful painting.

\subsection{THE MONIST STRATEGY}

The final account of aesthetic obligations requires a little more care. It has not been fully articulated as an account of aesthetic obligations, but it is perfectly plausible as such. This account takes its inspiration from Dom Lopes's recent account of aesthetic value, which incorporates normative terms that suggest a close relationship with deontic reasons.

Aesthetic values, according to Lopes, are essentially practical - they provide reasons for action. ${ }^{11}$ And reasons for action are just reasons that lend weight to what one ought to do. The fact that the new Jim Jarmusch film is good gives you reason to go see it. Aesthetic values provide reasons for action by lending weight to the fact that you ought to take some aesthetic action. You have aesthetic reason to see the new Jarmusch film when you ought to go see it. Lopes's account of reasons connects to a 'should' claim:

the fact that $\mathrm{x}$ is $\mathrm{V}$ is an aesthetic reason for $\mathrm{A}$ to $\varphi$ in $\mathrm{C}=$ the fact that $\mathrm{x}$ is $\mathrm{V}$ lends weight to the proposition that A aesthetically should $\varphi$ in C. (Lopes 2018, p. 38)

Aesthetic values just are reasons to undertake some action, and reasons just are things that you should do.

The claim that reasons just are things that you should do is reminiscent of a common view that reasons are constitutively deontic: What it is for something to be a reason is just for it to support a normative requirement. (As we will see, there are reasons to think that Lopes would not take this route. But Lopes does take this view to be consistent with the view that there are aesthetic obligations, and this monist interpretation offers a way to support such a claim.) According to this view, reasons always issue or contribute to directives because we always ought to do what we have most reason to do. It is wrong not to act on one's reason unless one has a countervailing reason. Let us call this view monism about reasons, because it holds that all reasons share the same normative profile: They are deontic in force. ${ }^{12}$ As Jonathan Dancy characterizes this view, 'the term 'reason' means (among other things, perhaps) a consideration which one would be wrong not to act on in the absence of any opposition' (Dancy 2004, p. 92).

If reasons in general are deontic, then so are aesthetic reasons. And therefore, because we defined an obligation as a deontic reason, it follows trivially that there are aesthetic obligations. Let us call this argumentative strategy the Monist Strategy, because the strategy proceeds from a monist account of the normative force of reasons.

Some philosophers have thought that values reduce to reasons. So if all reasons are deontic, then values are deontic, too. Christine Tappolet 
describes this view as follows: 'To be valuable or good would be nothing else than to have natural properties that make it the case that one ought ... to act or react in certain ways. An imperative would lie at the heart of values.' (Tappolet 2005, p. 397) This means that all value is deontic; there is no distinction in kind between the right and the good, only a distinction of weight.

The Monist Strategy is an elegant strategy. It is simple. And it succeeds where the Relational Strategy fails. For it explains the intuitive cases - cases that Lopes cites in motivating the view that there are aesthetic obligations. Monism explains why we ought to save the drowning painting just in virtue of the thing's value: The painting's beauty presents reasons for us to save it.

But I believe the Monist Strategy should not be adopted so quickly. In the next section, I present an alternate account of reasons.

\section{Enticing reasons}

According to an alternative model of aesthetic reasons from a familiar meta-normative position, not all reasons are deontic in force. Some reasons have a non-deontic normative profile.

Following up on a suggestion from Joseph Raz (1999), Jonathan Dancy (2004) has argued against the monist view of reasons. Dancy argues that some reasons do not create oughts or obligations; some reasons make options appealing, but they do not demand. Dancy calls these reasons 'enticing reasons' ${ }^{13}$ Dancy writes: 'A set of enticing reasons can be sufficient to make the action they recommend worth doing, fun, exciting, attractive, and so on' (Dancy 2004, p. 99). Enticing reasons never mandate or compel; it is not wrong to ignore the call of an enticing reason. An enticing reason, writes Dancy, is 'a reason that it is not wrong to fail to respond to, in the absence of opposing considerations' (Dancy 2004, p. 92).

Here's an example similar to Dancy's: Suppose you are thinking about seeing a play tonight. Let us say it's Annie Baker's play The Flick. The Flick is a great play, and this is a reason to see it. But suppose you just lounge around at home instead. If so, you have not done wrong, even though you may be acting silly. This is because a reason to see a play is not a duty; it does not have deontic force. ${ }^{14}$ Instead, it is a merely enticing reason.

Not all enticing reasons, Dancy claims, are enough to make their options worthwhile. Just because an option has an enticing reason in its favor does not mean it is worthwhile. To be worthwhile, enticing reasons must be sufficient. And multiple enticing reasons can be sufficient. Dancy writes that 'An enticing reason (or a set of enticing reasons) is sufficient if it makes its option worth doing. There may be more than one thing that is worth doing, as things stand' (Dancy 2004, p. 95). ${ }^{15}$

If enticing reasons do not have any deontic force, what grounds them as reasons? Why do not they make demands? One way of thinking about 
enticing reasons says that they are not binding because they are grounded in subjective, non-universal preferences. On this view, a reason has deontic force only when it has universal applicability - and because aesthetic reasons lack universal applicability, they do not have deontic force. (McGonigal 2018 suggests this line of argument regarding aesthetic obligations.) Dancy considers this account of enticing reasons. But he argues against it: Many deontic reasons lack universal applicability (e.g. obligations to particular loved ones). So the categorical/personal distinction is not a useful way to mark the boundary between deontic and enticing reasons. Instead, Dancy suggests, enticing reasons are distinctive in virtue of their functions - they have a unique style of outputs. Whereas deontic reasons take us to oughts, enticing reasons take us to bests. On this account, enticing reasons are evaluative without being deontic in virtue of their unique teleology. We might compare this to the debate about requiring, justifying, and favoring force of reasons (Horgan and Timmons 2010, Portmore 2011, and Archer 2016). Reasons can favor certain acts of appreciation, and they can justify those acts of appreciation; but they can do so without requiring us to appreciate things.

One might worry that enticing reasons come apart from evaluation; we might be enticed by aesthetically bad objects. However, this is to misunderstand enticing reasons. Enticing reasons are not subjective properties having to do with desire. They are rooted in the objective evaluative properties of objects.

Margaret Little (2013) bolsters the case for enticing reasons. She says: We often think of the justificatory force of reasons as being deontic. Think, for example, of reasons to act morally or reasons to believe something. But, Little argues, justificatory reasons do not have this weight in other realms. She provides two examples of justificatory reasons that are not deontic: (1) Fittingness in emotions. Emotions are often warranted - think of anger but we do not always think that one ought to have that emotion. Sometimes, emotions are justified but not required. You are permitted to get angry at the person who cuts in front of you in line, but there's no sense in which you ought to get angry at them. (2) Doing something sweet for one's partner. Sweet actions for a loved one are nice to do, and they are justified. But one is not wrong for not doing them - otherwise one would be required to do something sweet for one's partner at every moment! Little argues that we ought not to confuse a reason's justificatory force with its deontic force, because the two come apart. ${ }^{16}$

R. Jay Wallace argues for enticing reasons with slightly different terminology. Wallace distinguishes deontic reasons (claims about what an agent ought to do) from aspirational reasons (claims about what it would be best do to). Wallace distinguishes three cases. In one case, MOVIE, you have a choice between going to see an Antonioni film or staying home and watching some trash TV. The reason does not have deontic force; it would be good to see the Antonioni film, but you do not have to. In another case, 
SMALL LOAN, you have a choice between paying your credit card bill or not. Here, you have a deontic reason, but it is purely practical; it seems that you ought, practically, to pay the loan. In another case, DISTRAUGHT FRIEND, it seems you ought to comfort a distraught friend rather than attend an unimportant meeting. Here, you have a deontic reason in a moral sense. You ought, morally, to comfort your friend. According to Wallace, this shows something important about the structure of normativity in general. Wallace considers what he calls a teleological approach to normativity, according to which 'the fundamental normative relation is the productive relation that our potential actions stand in to valuable states of affairs' (Wallace 2013, p. 160). The teleological approach to normativity says that one ought to promote value. If this is true, there is no room for the purely aspirational normativity in MOVIE. So, Wallace concludes, the teleological approach must be wrong. Notice that the argument here will apply against monism.

Wallace gives an alternative picture of obligation, according to which deontic demands are necessarily second-personal. ${ }^{17}$ To make a moral demand is to make a demand of someone. Aesthetic reasons are precisely not secondpersonal.

Unlike, say, an aesthetic response, ... moral blame makes a demand; it addresses the charge of having acted culpably, that is, having done wrong, violated an all-things-considered moral obligation, without adequate excuse. It holds someone answerable in a way that third-personal responses like aesthetic attitudes do not. (Wallace 2013, p. 220).

The main lesson is that the monist account of reasons is not the only game in town. And, because the most prominent strategy for aesthetic obligations rests upon this account, we should at least be hesitant about accepting the Monist Strategy. This also puts us in a position to see why aesthetic reasons just cannot be deontic.

\section{Aesthetic reasons are merely enticing reasons}

Suppose we give up the monist picture and accept that there are enticing reasons. My claim here is that all aesthetic reasons are merely enticing reasons.

It's clear that some aesthetic reasons are enticing. Both Dancy and Wallace offer aesthetic reasons as paradigmatic instances of enticing reasons. But why think that all aesthetic reasons are enticing? I cannot offer a complete defense, but I'll offer one consideration. The view that all aesthetic reasons are enticing explains one striking fact that many have found compelling about the aesthetic realm: Aesthetics is a realm of freedom. The way I am thinking of it here, 'freedom' has to do with negative freedom; it is freedom from anything. ${ }^{18}$ 
Many thinkers have emphasized the importance of play in aesthetic life. Famously, Kant (1793) emphasizes aesthetic experience as essentially involving a free play of the faculties. Schiller says that play lies the heart of beauty: 'With beauty shall man only play, and it is with beauty only that he shall play' (Schiller 15.8, p. 107). Something sounds wrong about a life where our aesthetic choices are required rather than free. Play - in Schiller's sense involves the ability to experiment. When you play, you are not forced to choose the best option. If aesthetic reasons were deontic, we would be compelled to always choose the best option.

Hilde Hein distinguishes several elements in Schiller's aesthetic account of play. I want to focus on her point that aesthetic play is free from compulsion.

Play consists in the functioning of the faculties in the fashion to which they are normally adapted, cognitive as well as physical, but without the compulsion of either internal pressures or external demands. (Hein 1968, p. 67)

A beautiful painting or album strikes us in a way that may seem like we need to listen to it - but there is no pressure that we ought to do so. When Schiller says that 'With beauty shall man only play,' he is suggesting that the most we can do with beauty is play with it.

Of course, some play is competitive. Competitive play is demanding; it involves pressure. In a good game of poker or hockey, you need to maximize chips or goals. But competitive play is not Schillerian play. Schillerian play is open-ended. Think of a child playing with a toy truck; this play does not involve any pressure to maximize. If we had a duty to aesthetically maximize, we would not be able to explore in natural and spontaneous ways. But this exploration is what makes aesthetic activities so fun - and so important.

This is kind of play that the great film critic Pauline Kael had in mind when, in her famous essay 'Trash, Art, and the Movies,' she argued that the great virtue of trash movies was that they do not demand anything from us - they do not involve duty. Part of Kael's point is that much of what passes for received high art exerts pressure on us to have a certain response; this pressure itself, Kael says, robs us of the freedom necessary for aesthetic life.

Perhaps the single most intense pleasure of moviegoing is this non-aesthetic one of escaping from the responsibilities of having the proper responses required of us ... And yet this is probably the best and most common basis for developing an aesthetic sense because responsibility to pay attention and to appreciate is anti-art, it makes us too anxious for pleasure, too bored for response. Far from supervision and official culture, in the darkness at the movies where nothing is asked of us and we are left alone, the liberation from duty and constraint allows us to develop our own aesthetic responses. (p. 104)

Kael claims that 'liberation from duty and constraint' is necessary for aesthetic responses themselves. But her comments suggest further that freedom 
is necessary for aesthetic education. Of course, part of Kael's point here is that developing our own aesthetic response requires freedom from other voices. This is a point about autonomism - we need to cultivate our own appreciations from an essentially first-person point of view. But it is also a claim about the structure of aesthetic appreciation: appreciation in general must be free from duty and constraint.

Someone who endorses the monist account of reasons may try to show that aesthetic reasons allow for freedom even if they are deontic. For example, Jerrold Levinson argues that we are free to choose between aesthetic options to the extent that these options on an evaluative par with each other (2010, p. 231). You have freedom to choose between (for example) music by Kendrick Lamar, stories by Alice Munro, or movies by Abbas Kiarostami. Works by these artists are, let us suppose, the best in their genres. And because they are all on a par, you are free to choose between them. However, it's not clear that this is real freedom. It's not the kind of freedom which will allow for flourishing aesthetic lives. Under this monist view, the pressure is still on for us to perform at our aesthetic best. My claim instead is that it's permissible for you to knowingly choose what you know is not the best. To demand otherwise is to allow an element of compulsion in our aesthetic lives. As Margaret Little (2013) points out, being a free agent seems to require the ability to act freely even in the face of conclusive or optimizing reasons. This is the freedom that aesthetic reasons offer. And it's different from moral freedom. (Even Jonathan Dancy (2004, p. 99) points out the freedom of enticing reasons: 'one is, as it were, in charge of one's enticing reasons. It is never irrational or wrong to choose an enticing action other than the one that is most enticing - even though it can be pretty silly to do so, and, in this weak sense, contrary to reason.')

Finally, consider a person who Alex King calls the indifferent anaesthetic: someone who recognizes what's beautiful but does not feel a pull to pursue it. Intuitively, there's nothing truly wrong with such a person (King 2018). If aesthetic reasons only entice and do not demand, there's nothing incoherent with both recognizing an aesthetic reason and not feeling compelled to act upon it. King's point is that motivational internalism seems particularly implausible in the aesthetic realm. To my mind, this point helps to explain the freedom of the aesthetic realm. And, in turn, it helps to explain why beauty offers goods without shoulds.

My argument here is consonant with other claims that there are no aesthetic obligations. Consider what Martha Nussbaum says:

I can, visiting a museum, survey many fine objects with appropriate awe and tenderness. I can devote myself now to one, now to another without the sense that the objects make conflicting claims against my love and care. If one day I spend my entire museum visit gazing at Turners, I have not incurred a guilt against the Blakes in the next room. (1990, p. 132) 
My claim that aesthetic reasons are enticing reasons explains Nussbaum's language here, that art has power over us without our incurring an obligation to it. ${ }^{19}$

\section{Objections}

The first objection is that the monist can accommodate freedom in a different way. One might hold that there are different degrees of deontic force: Aesthetic reasons may carry deontic force, but it is not serious enough to challenge our freedom. Lopes himself takes this kind of line: 'Morality has no lock on normativity, and not all normativity is heavy-duty normativity.' (Lopes 2018, p. 40) According to Lopes, aesthetic reasons can have deontic force, but without being serious. 'We wonder what we should do, even when there is no dilemma in sight, nothing serious at stake, and no impending guilt or shame.' (Lopes 2018, p. 40). Likewise, John Broome argues against Dancy's picture of enticing reasons (Broome 2013, pp. 60-61). Broome claims that you should do what your reasons say, even when it comes to aesthetic matters like eating mangosteens. But, Broome says, these shoulds are not obligations. According to this response, aesthetic reasons are deontic to some extent, but they are not serious enough to count as heavy-duty shoulds. We still have freedom.

In response, I'm happy to allow that some shoulds are not deontic. But that just makes them 'shoulds' of enticing reasons. Recall that, for Dancy, enticing reasons may be conclusive reasons. Perhaps enticing shoulds are just conclusive shoulds. But it does not follow that one really ought to comply with these reasons, or that it is wrong not to. Indeed, taking this line allows me to explain the cases of 'oughts' and 'shoulds' at the beginning of the paper. While there may seem to be aesthetic shoulds, they are not normatively strong enough to rise to the level of obligations.

But this raises a larger issue about what Wallace calls the teleological approach to normativity - the view that all reasons contribute to directives. ${ }^{20}$ It raises the issue of whether evaluation and normativity are essentially bound up together. A full analysis of the teleological approach may be beyond this essay. But I hope to have at least presented and motivated a competing approach according to which there are non-teleological reasons.

A second objection is that there are clear obligations in some realms of art. For example, it seems clear that performers ought to play the notes of the score. On one account, they owe this to the composer (Sharpe 2000, p. 323). I deny that these are genuine obligations. Elsewhere, I argued that these obligations are less serious than they seem; throughout western 
fine-art music, performers have frequently disregarded notes of the score (Dyck 2014). However, there is still a problem that such a norm exists in many circles; how do we deal with those instances? This norm pertains to performance. It does not center on appreciation, which is the case I focus on here. ${ }^{21}$

Relatedly, one may point out that certain genres or categories have constitutive normative rules about what it means to be good in a genre. Consider, for example, Chekhov's dictum: if there is a loaded gun introduced at the beginning of a story, the gun ought to go off before the end of the story. In reply, notice that this objection implies a form of artistic generalism, the view that there are general principles of artistic value. A full discussion of generalism and particularism is beyond the scope of this essay. But there are many reasons to be skeptical about aesthetic or artistic generalism, not least of which is that satisfactory general rules of artistic or aesthetic value have yet to be articulated. It's easy to imagine a good play in which a loaded gun, introduced in the first act, plays an important role in creating tension but never goes off.

Another objection comes from the following case: Imagine someone who does not care about aesthetic value. They do not seek out beauty; they do not appreciate beauty when it comes around. It is not that this person is hostile to aesthetics, or that they are a crank. We can imagine that they live a happy life, surrounded by good friends, and doing a great amount of good. They are a scrooge, but an exclusively aesthetic scrooge. There seems to be something intuitively wrong with Aesthetic Scrooge: They do not live up to the demand that they ought to undertake some aesthetic exploits. This suggests that everyone ought to appreciate some aesthetic value in their lives. But this is an aesthetic obligation. So there is an aesthetic obligation to appreciate some things, at least sometimes.

I am unconvinced that there is anything wrong with Aesthetic Scrooge - I appealed to King earlier in defense of such a person. But it's not a problem for my view if Aesthetic Scrooge seems bad to you. While this might be some kind of aesthetic obligation, it is not the kind of obligation that is the subject of this paper. This example shows only that we should make room in our lives for the aesthetic domain. It does not tell us how to fill that domain. The question of whether we ought to fill our aesthetic domains some particular way or other, I take it, is the central question about aesthetic obligation - at least, it is the question that has occupied the literature on aesthetic obligations. That is different from the question of whether we ought to fill our aesthetic domains at all. As such, there may be imperfect duties in aesthetics: duties to take up aesthetic ends. But there are no perfect duties - duties to perform specific actions. ${ }^{22}$

The final objection comes from cases where we weigh moral reasons against aesthetic reasons. Consider a debate between installing more lights in a highway - for safety - or no lights - for beauty. ${ }^{23}$ Here we have a 
debate between moral reasons and aesthetic reasons. People may choose not to install the lights because of aesthetic value. Yet, if aesthetic reasons are merely enticing, how could they ever stand up to moral reasons? If I am right, then moral reasons and aesthetic reasons are not of a piece. And if they are not of a piece, then they cannot be compared against each other. Yet they are compared against each other. So (the objection goes) I am wrong.

In response, I allow that enticing reasons are often compared against deontic reasons. And I allow that enticing reasons often win out. Tonight, I'm going to spend my money at the movies rather than at Oxfam. We can still compare these reasons against each other even though they are two different realms of reasons, with different normative profiles.

\section{Conclusion}

What are we to say about the apparent aesthetic obligations we started with? They may have some intuitive pull still. Instead of aesthetic obligations, they may carry some social force or some developmental force.

This discussion has assumed that aesthetic properties and reasons can be carved out from other kinds of properties and reasons. If one thinks that the aesthetic is essentially bound up with the moral or political, the whole issue quickly loses steam. I have not argued here for the autonomy of the aesthetic realm; I have taken that for granted, because it seems to be assumed by the core question. My argument, then, shows that there are no purely aesthetic obligations.

The claim, then, is not that we are free to do what we like in any aesthetic matter whatever. For the aesthetic domain frequently overlaps with the moral and social domains. The claim here is only that the aesthetic realm is distinct in kind from the moral and the social. Many aesthetic questions overlap with heavy weight of culture, in which aesthetic, social, and political values arise with pressing urgency. In practice, aesthetic values swirl around with social and moral values and obligations: Obligations to do right by each other in how we treat one another's art and bodies and minds. But to say that these obligations are aesthetic sells short their important second-personal nature.

Of course, one may reject the autonomist assumption. One may say that the aesthetic domain is not separate from social and moral realms. I often find this view tempting myself. On this view, the question's answer becomes obvious: Of course there are aesthetic obligations, because our obligations to each other bleed into the aesthetic realm. ${ }^{24}$

My thesis has consequences for how we carve up evaluation and normativity. It suggests that the normative contours of the aesthetic domain 
may not map neatly onto a meta-ethical framework. As we try to carve up reasons, normativity, and evaluation, we need to pay attention to the unique normative profile of the aesthetic realm. ${ }^{25}$

\section{Department of Philosophy Auburn University}

\section{NOTES}

1 See, for example, Feldman (1988), Papineau (2013), Weatherson (2008).

2 Thanks to Thi Nguyen for this example.

3 Cross qualifies the source but not the nature of aesthetic obligations, claiming only that aesthetic obligations derive from rights; 'works of art are the bearers of moral rights which generate corresponding obligations ... on the part of individuals who interact with those artworks' (Cross 2017b, p. 89).

4 Here I follow Andrew McGonigal's (2018) liberal account of aesthetic properties.

5 If you are not convinced that aesthetic reasons for appreciation and attention are central, then you can just qualify my conclusion: There are no obligations of aesthetic appreciation. That's still a significant claim.

6 There are other strategies. For instance, Archer and Ware (2017) argue that there is a distinctively aesthetic form of blame that targets responsibility. Thanks to an anonymous referee for drawing this to my attention.

7 Cross discusses obligations to artworks, not to aesthetic objects. In a later paper, however, he clarifies that the view can be extended to aesthetic objects in general (Cross Unpublished MS.).

8 'On the morning of our departure ... my mother ... found me standing in tears on the steep little path close to Tansonville, bidding farewell to my hawthorns, clasping their sharp branches in my arms. ... 'Oh, my poor little hawthorns', I was assuring them through my sobs, 'it is not you who want to make me unhappy, to force me to leave you. You, you have never done me any harm. So I shall always love you'. And, drying my eyes, I promised them ... I would never copy the foolish example of other men, but that even in Paris, on fine spring days, instead of paying calls and listening to silly talk, I would set off for the country to see the first hawthorn-trees in bloom.' (Proust 1992, pp. 203-204.)

9 Kubala's account takes inspiration from Richard Moran's (2012) claim that beauty, in some sense, stakes a claim on us - a claim that is binding without being universal.

10 Cross's account requires that the object have some merit in the first place. But this meriting property does not ground the obligation itself; it is only necessary for the obligation.

11 Some may see this claim as at odds with my claim that appreciation is central to the aesthetic realm. I'm not so sure; it's plausible that appreciation might be a kind of mental action. Anyway, I do not think that anything hangs on this characterization of the aesthetic here.

12 How exactly the normative demand gets spelled out need not concern us here. Perhaps every reason has its own pro tanto obligation. Or perhaps obligations pertain to all-thingsconsidered reasons, or to overriding reasons. As Lopes acknowledges, aesthetic reasons may not always be decisive (Lopes 2018, p. 39).

13 Dancy repurposes the notion of enticing reasons from Raz (1999). Raz writes that 'Failure to conform with enticing reasons is never wrong, unreasonable, or irrational' (Raz 1999, p. 100). 
14 In a way, this is the inverse of the suberogatory (Driver 1992) - actions that are bad but still permissible.

15 Dancy spends time in this essay getting clear on what exactly deontic reasons - or, as he calls them, peremptory reasons - do or do not involve. Dancy claims, for example, that conclusive reasons may be enticing, not just deontic. Dancy defines a conclusive reason as 'a consideration which, though there may be others on both sides, really is the one that decides the issue in the present case' (Dancy 2004, p. 94). And he claims that overall reasons also may be enticing rather than just deontic: 'though there can be both enticing and requiring reasons, the requiring reasons, no matter how weak, will always win in a head-to-head fight' (Dancy 2004, p. 99).

16 For more on justifying vs requiring reasons, see Gert 2003, 2007.

17 See also Darwall (2006).

18 Thanks to Alex King for discussion on this point.

19 Stuart Hampshire (1954) argued that aesthetic objects never make obligations because they never present pressing reasons for action - aesthetics never demands for us to act immediately. This move requires that aesthetic reasons cannot be related to practical reasons. That's too strong.

20 Elsewhere, Lopes (2014) draws heavily upon Judith Jarvis Thomson's (2008) teleological account of normativity.

21 Thanks to Julian Dodd for helpful comments on this point. Rohrbaugh (2020) argues that the demand to play the notes is simply part of some musical practices.

22 Thanks to Henry Pratt and to an anonymous referee for this journal for discussion on this point.

23 Thanks to Derek Matravers for this example.

24 Thanks to Katie Brennan for discussion on this point.

25 This paper was presented at the Aesthetic Normativity Workshop in Padova, the CUNY dissertation workshop, the Canadian Philosophical Association 2018 meeting in Montreal, and at the American Society for Aesthetics Annual 2018 meeting in Toronto. Thanks to audiences at those presentations, and thanks to Robbie Kubala and Ira Newman for helpful comments. Thanks to Elisa Calderola for her invitation to present at the normativity workshop, and for her helpful discussion. Thanks to Anthony Cross, Saul Fisher, Alex King, Samantha Matherne, Dominic McIver Lopes, Per Milam, Thi Nguyen, Nick Riggle, Kate Ritchie, Giuseppe Spolaore, and Brian Soucek for insightful comments on previous versions of this paper.

\section{REFERENCES}

Archer, A. (2016). 'Moral Obligation, Self-Interest, and the Transitivity Problem,' Utilitas 28, pp. 441-464.

Archer, A. and Ware, L. (2017). 'Aesthetic Supererogation,' Estetika 54, pp. 102-116.

Archer, A. and Ware, L. (2018). 'Beyond the Call of Beauty: Everyday Aesthetic Demands under Patriarchy,' The Monist 101, pp. 114-127.

Broome, J. (2013). Rationality through Reasoning. Malden: Wiley-Blackwell.

Calhoun, C. (2009). 'What Good Is Commitment?' Ethics 119(4), pp. 613-641.

Cross A. (2017a). 'Art Criticism as Practical Reasoning,' British Journal of Aesthetics 57, pp. 299-317.

Cross, A. (2017b). 'Obligations to Artworks as Duties of Love,' Estetika 54, pp. 85-101.

Cross, A. (Unpublished MS.). Aesthetic Obligations.

Dancy, J. (2004). 'Enticing Reasons,' in Wallace, Pettit, Scheffler and Smith (eds) Reason and

Value: Themes From the Moral Philosophy of Joseph Raz. Oxford: Clarendon Press.

Darwall, S. (2006). The Second-Person Standpoint. Cambridge: Harvard University Press.

Driver, J. (1992). 'The Suberogatory,' Australasian Journal of Philosophy 70, pp. 286-295. 
Dyck, J. (2014). 'Perfect Compliance in Musical History and Musical Ontology,' The British Journal of Aesthetics, 54(1), pp. 31-47.

Eaton, M. M. (2008). 'Aesthetic Obligations,' The Journal of Aesthetics and Art Criticism 66, pp. $1-9$.

Feldman, R. (1988). 'Epistemic Obligations,' Philosophical Perspectives 2, pp. 235-256.

Gert, J. (2003). 'Requiring and Justifying: Two Dimensions of Normative Strength,' Erkenntnis 59 , pp. 5-36.

Gert J. (2007). 'Normative Strength and the Balance of Reasons,' Philosophical Review 116, pp. 533-562.

Gorodeisky, K. (Forthcoming). 'The Centrality of Appreciation,' in Ferrero, L. (ed) Routledge Handbook for the Philosophy of Agency. Abingdon: Routledge.

Hampshire, S. (1954). 'Logic and Appreciation,' in E. Ed (ed.) Aesthetics and Language. Oxford: Blackwell.

Hein, H. (1968). 'Play as an Aesthetic Concept,' The Journal of Aesthetics and Art Criticism 27, pp. $67-71$.

Horgan, T. and Timmons, M. (2010). 'Untying a Knot from the Inside Out: Reflections on the "Paradox" of Supererogation,' Social Philosophy and Policy 27, pp. 29-63.

Kant, I. (1793/2001). 'Critique of the Power of Judgement'. Trans Guyer and Matthews. Cambridge: Cambridge UP.

King, A. (2018). 'The Amoralist and the Anaesthetic,' Pacific Philosophical Quarterly 99, pp. 632-663.

Kubala, R. (2018). 'Grounding Aesthetic Obligations,' British Journal of Aesthetics 58, pp. 271-285.

Levinson, J. (2010). 'Artistic Worth and Personal Taste,' Journal of Aesthetics art Art Criticism, 68(3), pp. 225-233.

Little, M. (2013). 'In Defense of Non-Deontic Reasons,' in Bakhurst, Hooker and Little (eds) Thinking about Reasons: Themes from the Philosophy of Jonathan Dancy. New York: Oxford University Press.

Lopes, D. M. (2018). Being for Beauty. Oxford: Oxford University Press.

McGonigal, A. (2017). 'Responding to Aesthetic Reasons,' Estetika 2017, pp. 40-64.

McGonigal A. (2018). 'Aesthetic Reasons,' in Star (ed.) Oxford Handbook of Reasons and Normativity. New York: Oxford University Press.

Moran, R. (2012). 'Kant Proust, and the Appeal of Beauty,' Critical Inquiry 38, pp. 298-329.

Nussbaum, M. (1990). Love's Knowledge: Essays on Philosophy and Literature. Oxford: Oxford University Press.

Papineau, D. (2013). 'There Are No Norms of Belief,' in Chan (ed.) The Aim of Belief. New York: Oxford University Press.

Portmore, D. (2011). Commonsense Consequentialism: Wherein Morality Meets Rationality. Oxford: Oxford University Press.

Press, H. (1969). 'Aesthetic Obligation,' Journal of Philosophy 66, pp. 522-530.

Proust, M. (1992). Swann's Way. Translated by C.K. Scott Moncrieff and T Kilmartin (eds). New York: Vintage.

Raz, J. (1999). Engaging Reason: On the Theory of Value and Action. Oxford: Oxford University Press.

Rohrbaugh, G. (2020). 'Why Play the Notes? Indirect Aesthetic Normativity in Performance,' Australasian Journal of Philosophy 98, pp. 78-91.

Sharpe, R.A. (2000). 'The Empiricist Theory of Artistic Value,' The Journal of Aesthetics and Art Criticism, 58(4), pp. 321-332.

Tappolet, C. (2005). 'Values, Reasons, and Oughts,' in Reicher and Marek (eds) Experience and Analysis. Wien: OBV \& HPT. 
Thomson, J. J. T. (2008). Normativity. London: Open Court.

Wallace, R. (2013). 'The Deontic Structure of Morality,' in Bakhurst, Hooker and Little (eds) Thinking About Reasons: Themes from the Philosophy of Jonathan Dancy. New York: Oxford University Press.

Weatherson, B. (2008). 'Deontology and Descartes' Demon,' The Journal of Philosophy (105), pp. 540-569. 